University of Nebraska - Lincoln

DigitalCommons@University of Nebraska - Lincoln

Faculty Publications, Department of Psychology

Psychology, Department of

2-2010

\title{
Gender Moderates the Association between 5-HTTLPR and Decision-making under Ambiguity but Not under Risk
}

\author{
Scott F. Stoltenberg \\ Black Hills State University, sstoltenberg2@unl.edu \\ Joanna M. Vandever \\ Black Hills State University, joanna.vandever@colorado.edu
}

Follow this and additional works at: https://digitalcommons.unl.edu/psychfacpub

Part of the Genetics Commons, and the Psychology Commons

Stoltenberg, Scott F. and Vandever, Joanna M., "Gender Moderates the Association between 5-HTTLPR and Decision-making under Ambiguity but Not under Risk" (2010). Faculty Publications, Department of Psychology. 1023.

https://digitalcommons.unl.edu/psychfacpub/1023

This Article is brought to you for free and open access by the Psychology, Department of at DigitalCommons@University of Nebraska - Lincoln. It has been accepted for inclusion in Faculty Publications, Department of Psychology by an authorized administrator of DigitalCommons@University of Nebraska - Lincoln. 


\title{
Gender Moderates the Association between 5-HTTLPR and Decision-making under Ambiguity but Not under Risk
}

\author{
Scott F. Stoltenberg, ${ }^{1}$ and Joanna M. Vandever ${ }^{2}$
}

Department of Psychology, Black Hills State University, Spearfish, South Dakota, USA

1. New address: Department of Psychology, University of Nebraska-Lincoln, 238 Burnett Hall, Lincoln, NE 68588308, USA

2. New address: Institute for Behavioral Genetics, University of Colorado, Boulder, CO 80303, USA; email joanna.vandever@colorado.edu

Corresponding author - Scott F. Stoltenberg, telephone 402-472-7861, email sstoltenberg2@unl.edu

\begin{abstract}
Decisions made under ambiguity may involve a different genetic architecture than those made under risk. Because gender moderates the effect of genetic polymorphisms on serotonin function and because there are gender differences in decision-making, the present study examined potential gender moderation of associations between polymorphisms in important serotonin system candidate genes (serotonin transporter [SLC6A4] and tryptophan hydroxylase-2 [TPH2]) and performance on a decision-making task (Iowa Gambling Task, IGT) in healthy, adults ( $N=188 ; 62 \%$ women). Subjects were genotyped for the well-studied SLC6A4 promoter variant 5-HTTLPR and a TPH2 single nucleotide polymorphism in intron-8 (rs1386438). Genotype at rs1386438was not associated with performance on the IGT. A significant gender by 5-HTTLPR genotype interaction effect was detected when decision-making was under ambiguity (i.e., the first block of 20 choices) but not under risk (blocks 2-5). Performance on the first block of 20 choices was not correlated with performance on subsequent blocks, supporting the interpretation that early performance on the IGT indexes decision-making under ambiguity, while performance on blocks $2-5$ indexes decision-making under risk. These findings suggest that decision-making under ambiguity and risk may have different genetic architectures and that individual differences in decision-making under ambiguity are associated with genetic variation in SLC6A4.
\end{abstract}


Keywords: serotonin, decision-making, Iowa gambling task

\section{Introduction}

People routinely make decisions when there is uncertainty about the outcome probabilities that will result from different choices. Poor decision-making can increase the probability of engaging in health-risk behaviors and the development of behavioral disorders (Dolan et al., 2008; Schilt et al., 2008; Tevendale et al., 2008; van der Plas et al., 2008).

There are two types of decisions under uncertainty distinguished by the degree of uncertainty about outcome probabilities. Decisions under ambiguity are those with unknown outcome probabilities. Deciding whether to drink a shot of tequila is an example because one cannot assign outcome probabilities to the decision. Decisions under risk are those with known outcome probabilities. Deciding to bet on red while playing Roulette is an example because the outcome probabilities can be specified.

The Iowa Gambling Task (IGT) is a task with mixed (both gain and loss) gambles (Bechara et al.,1994) that has been used widely to study individual differences in decisionmaking. In the IGT, participants choose cards from four decks that vary systematically in the level of gain and loss. Initially, outcomes are ambiguous because participants do not yet know the outcome probabilities associated with choosing from particular decks. As the task progresses participants learn the outcomes associated with different decks and therefore, at some point, the IGT begins to assess decision-making under risk (Brand et al., 2007). Although there is some disagreement about the amount of knowledge participants have about the contingencies in the IGT and when that knowledge affects performance (Bechara et al., 2005; Maia and McClelland, 2004), participants should gain knowledge about task contingencies as the task progresses.

Decision-making under ambiguity and under risk may involve independent brain circuits and therefore may have different genetic architectures. Decision-making under ambiguity may involve a "limbic" loop of affective processing, whereas decision-making under risk may involve a "cognitive" loop (Brand et al., 2006). It may be possible to disentangle the contributions of the limbic (ambiguity) and cognitive (risk) loops to IGT performance by analyzing scores obtained early in the task (i.e., ambiguity) separately from those obtained later in the task (i.e., risk).

The serotonin system contains several genetic polymorphisms that affect aspects of system function that may be involved in decision-making (Haavik et al., 2008). The serotonin system innervates many brain areas related to decision-making, including the amygdala, the prefrontal cortex (orbital, ventromedial, and dorsolateral), and striatum (Baumgarten and Grozdanovic, 1999). Poor decision-making under conditions of risk has been associated with acute depletion of the dietary amino acid required to synthesize serotonin (tryptophan) (Rogers et al., 2003), and low serotonin levels are associated with an inability to delay gratification and detect changes in reward (Denk et al., 2005; van der Plasse et al., 2007). Finally, genetic polymorphisms in the serotonin system are associated with differences in amygdala activation to aversive or threatening stimuli (Brown et al., 2005; Hariri et al., 2005; Heinz et al., 2007; Lee and Ham, 2008). 
An important candidate polymorphism in the serotonin system is the serotonin transporter linked polymorphic region (5-HTTLPR), a promoter region polymorphism where the "short" allele is less transcriptionally active than the "long" allele (Lesch et al., 1996). Genetic variation in the serotonin transporter is associated with individual differences in ventromedial prefrontal cortex and amygdala activation (Hariri et al., 2005; Heinz et al., 2005, 2007) and performance on decision-making tasks (Roiser et al., 2006).

A gene that codes for tryptophan hydroxylase is another promising candidate gene. Variation in the neuronally expressed tryptophan hydroxylase gene (TPH2) is associated with individual differences in amygdala activation (Brown et al., 2005), response inhibition (Stoltenberg et al., 2006), decision-making (Jollant et al., 2007), and executive function (Reuter et al., 2007).

There is converging evidence that aspects of serotonin function differ for men and women. Gender differences have been identified in levels of serotonin and of cerebrospinal fluid 5-hydroxyindoleacetic acid (CSF 5-HIAA; (Ortiz et al., 1988)), serotonin synthesis (Nishizawa et al., 1997), and binding potential serotonin receptors (Biver et al., 1996). Furthermore, the genetic architecture of the serotonin system appears to differ for men and women (Weiss et al., 2005). There are also gender differences in IGT performance (Overman, 2004) and in patterns of brain activation during IGT performance (Bolla et al., 2004).

The present study examined potential associations between 5-HTT and TPH2 polymorphisms on IGT performance in a group of healthy men and women. We hypothesized that 5-HTTLPR and rs1386483 genotypes would be associated with individual differences in IGT performance and that these associations would be moderated by gender. We further hypothesized that these effects were likely to vary depending on whether decision-making was under ambiguity or risk.

\section{Material and methods}

\subsection{Participants and basic procedure}

College students $(N=200)$ participating in a larger study on impulsivity and health-risk behaviors served as subjects. The local Institutional Review Board approved the study and written informed consent was obtained from all individuals prior to study participation. To reduce the risk of population stratification, the present analysis included the $94 \%$ of participants who identified themselves as Caucasian ( $N=188 ; 71$ men, 117 women). Ages ranged from 18 to 47 years $(M=22.55, \mathrm{SD}=5.52)$. Participants were recruited using flyers and in-class presentations and were compensated $\$ 5$ for their time.

\subsection{Measures}

Participants completed a series of questionnaires and computer tasks designed to examine impulsivity and risky behavior; completed the $\mathrm{A}^{\prime}, \mathrm{B}^{\prime}, \mathrm{C}^{\prime}, \mathrm{D}^{\prime}$ version of the Iowa Gambling Task (IGT) (Bechara et al., 1994, 2000), with no monetary reward for performance; and donated buccal cells for genotyping. 


\subsection{Genetic analysis}

DNA was extracted from buccal cells and used in $20 \mu \mathrm{L}$ PCR reactions with $20-25 \mathrm{ng} / \mu \mathrm{l}$ of DNA per reaction. The serotonin transporter linked polymorphic region (5-HTTLPR) was amplified using the following primers: 5-HTTLPR-F: 5'-CGC TCT GAA TGC CAG CAC CTA ACC-3' and 5-HTTLPR-R: 5'-GGG ATT CTG GTG CCA CCT AGA CGC-3'. PCR conditions for 5-HTTLPR were 32 cycles of the following: $94^{\circ} \mathrm{C}$ for $45 \mathrm{~s}, 52^{\circ} \mathrm{C}$ for $45 \mathrm{~s}$, and $72^{\circ} \mathrm{C}$ for $1 \mathrm{~min}$ (Yonan et al., 2006). The intron- 8 polymorphism of tryptophan hydroxylase- 2 (rs1386483) was amplified using the following primers: TPH2-F: 5'-GCT GGC TCT GAA CGT GTA TTT TG-3' and TPH2-R: 5'-TTT GGC TGA TTT TCC TAATTA AT-3'. PCR conditions for TPH2were 34 cycles of the following: $94^{\circ} \mathrm{C}$ for $1 \mathrm{~min}, 52^{\circ} \mathrm{C}$ for $45 \mathrm{~s}$, and $72^{\circ} \mathrm{C}$ for $45 \mathrm{~s}$ and products were digested using 5.0U SspI (New England Biolabs). (Stoltenberg et al., 2006). Genotypes were visualized on agarose gels with ethidium bromide staining under UV light. For technical reasons, genotypes were available for 187 participants for 5-HTTLPR and 177 participants for TPH2. No other genetic polymorphisms were assessed for associations with IGT performance in this study.

\subsection{Statistical analysis}

Iowa Gambling Task net scores were calculated by subtracting the number of disadvantageous choices from the number of advantageous choices $\left(\left(\mathrm{C}^{\prime}+\mathrm{D}^{\prime}\right)-\left(\mathrm{A}^{\prime}+\mathrm{B}^{\prime}\right)\right)$ for each of five 20-card blocks. Repeated-measures ANOVAs were performed with gender and genotype as between subjects factors, block as a within subjects factor, and IGT net score as the dependent variable. Our initial statistical analyses grouped the 5-HTTLPR genotypes into two categories $\left(\mathrm{S} / \mathrm{S}+\mathrm{L} / \mathrm{S}=\mathrm{S} /{ }_{-}\right.$and $\left.\mathrm{L} / \mathrm{L}\right)$ to conserve statistical power and because of the evidence of the dominance of the $S$ allele for relatively lower transcriptional efficiency.We subsequently ran the same analyses with three 5-HTTLPR genotype groups and found no differences in the overall pattern of results (data not shown).

\section{Results}

\subsection{Allele and genotype frequencies}

For 5-HTTLPR, allele frequencies were 0.56 for the long allele $(\mathrm{L})$ and 0.44 for the short allele (S). Sixty-two participants were homozygous L/L, 86 were heterozygous L/S, and 39 were homozygous S/S. The genotype distributionwas in Hardy-Weinberg equilibrium, $\chi^{2}(2, N=187)=0.79, p>0.05$. For rs1386483, allele frequencieswere 0.73 for cytosine $(C)$ and 0.27 for thymine $(T)$. Ninety-six participantswere homozygous $C / C, 67$ were heterozygous

$\mathrm{C} / \mathrm{T}$, and 14 were homozygous $\mathrm{T} / \mathrm{T}$. The genotype distribution was in Hardy-Weinberg equilibrium, $\chi^{2}(2, N=177)=0.25, p>0.05$.

\subsection{Iowa gambling task performance}

Repeated-measures ANOVA, with IGT net scores across five blocks as the dependent variables and gender, 5-HTTLPR dichotomous (S/_ and L/L) and their interaction as factors, identified no significant between subjects effects. So, overall (i.e., pooled across blocks) IGT net score did not depend on gender or genotype. 
Within subjects analyses identified a highly significant block effect, $F(4,732)=54.78$, $p<0.001$. The pattern of net score change over block was significantly linear $F(1,183)=$ $111.47, p<0.001$, with quadratic $F(1,183)=31.62, p<0.001$, and 4 th order nonlinear characteristics $F(1,183)=5.01, p<0.04$. Mean net scores increased relatively linearly from -3.63 in block 1 to 7.02 in block 4 and then regressed slightly in block 5 to 6.52 . Overall, these results indicate participants made more advantageous choices as the task progressed.

Within subjects analyses also identified a highly significant block by gender interaction, $F(4,732)=6.95, p<0.001$. Contrasts indicated that the pattern of change across blocks for men and women was linear $F(1,183)=16.95, p<0.001$. Univariate $\mathrm{F}$ tests indicated that gender differences were significant in block $1 F(1,183)=7.49, p<0.008$ and in block 5 $F(1,183)=9.47, p<0.003$. Post hoc comparison of means indicated that women had a higher net score than men in block $1(-2.28$ and -5.46 , respectively) and that women had a lower net score than men in block 5 ( 4.49 and 9.41, respectively).

The within subjects effect for block by 5 -HTTLPR genotype was not significant, $F(4,732)$ $=0.27, p<0.95$. Within subjects analyses of the block by gender by 5-HTTLPR genotype, however, identified a highly significant effect $F(4,732)=3.89, p<0.005$, with a quadratic trend $F(1,183)=6.39, p<0.015$. Univariate $F$ tests indicated that the gender by 5 -HTTLPR genotype interaction effect was present only in block $1 F(1,183)=13.74, p<0.001$, when participants are most uncertain as to which decks are advantageous (i.e., ambiguity, see Fig. 1). In block 1 , men with the $\mathrm{L} / \mathrm{L}$ genotype made the most disadvantageous choices and women with the $\mathrm{L} / \mathrm{L}$ genotype made the fewest. Men and women with at least one short allele (i.e., S/_) performed similarly to each other in block 1 with mean net scores that were intermediate to those with L/L genotypes. Performance on block 1 was not significantly correlated with performance on any of the other IGT blocks (see Table 1). Correlations among blocks $2-5$ were all statistically significant (all $p<0.01$ ). This pattern of results is consistent with the interpretation that performance on block 1 indexes decisions under ambiguity and subsequent blocks index decisions under risk.

A repeated-measures ANOVA with IGT net score as the dependent variable revealed no main effect for rs1386483 genotype, $F(4,692)=0.68, p<0.65$. There was also no significant interaction effect for rs1386483 genotype and gender, $F(4,692)=0.38, p<0.85$. As expected, there was a significant block by gender interaction, $F(4,692)=3.75, p<0.006$. 


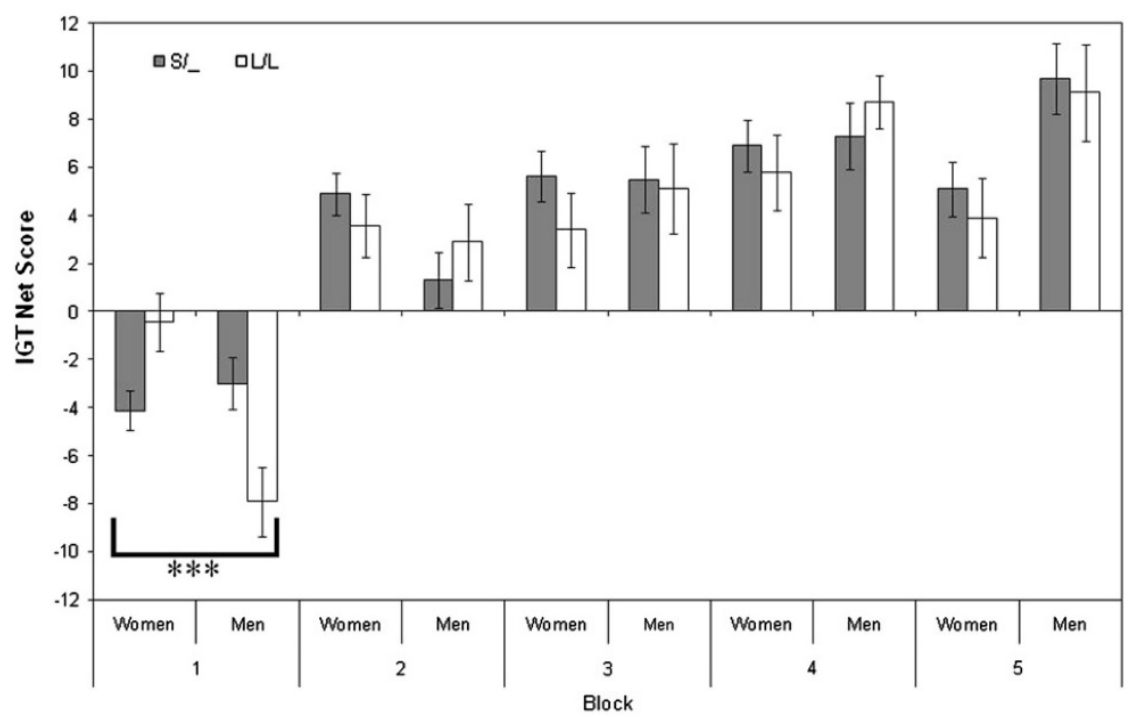

Figure 1. Mean net scores (advantageous-disadvantageous choices) on blocks (each consisting of 20 choices) one through five of the Iowa Gambling Task (IGT), for men and women grouped by 5-HTTLPR genotype (S/_ or L/L). Error bars represent the standard errors of the means. ${ }^{* *} p<0.001$.

\begin{tabular}{cccccc}
\hline \multicolumn{6}{l}{ Table 1. Correlations between scores on IGT blocks $(n=188)$} \\
\hline Block & 1 & 2 & 3 & 4 & 5 \\
\hline 1 & - & -0.09 & -0.01 & -0.11 & -0.14 \\
2 & - & $0.58^{* *}$ & $0.40^{* *}$ & $0.19^{* *}$ \\
3 & & - & $0.48^{* *}$ & $0.31^{* *}$ \\
4 & & & - & $0.59^{* *}$ \\
5 & & & & - \\
\hline
\end{tabular}

Note: Scores represent the net score (advantageous - disadvantageous decks) for each block of 20 choices. ${ }^{* *} p<0.01$

\section{Discussion}

Our results indicate that performance on the Iowa Gambling Task, when decisions are made under ambiguity, is associated with 5-HTTLPR genotype; and that the association is moderated by gender. Men with at least one short allele (S/_) made more advantageous choices than L/L homozygous men on the first block of the IGT. This finding is consistent with affective processing studies in which individuals with a short allele exhibit increased amygdala activation to fearful or ambiguous stimuli (Hariri et al., 2005; Heinz et al., 2007) and increased amygdala/ventromedial prefrontal cortex coupling (Heinz et al., 2005). In the first block, S/_ men may have been more sensitive than L/L homozygotes to the first large-losses of the disadvantageous decks - developing a preference for the advantageous decks more quickly. Women L/L homozygotes made more advantageous choices on the first block, which is not consistent with studies of 5-HTTLPR variation and amygdala 
reactivity. However, two of the three studies reviewed (Heinz et al., 2005, 2007) had allmale samples. More studies on 5-HTTLPR and amygdala activation that explicitly consider gender are needed to determine if the present finding is consistent with affective-processing in women.

When the datawere analyzed using three genotype groups (i.e., S/ S, L/S, and L/L, data not shown) instead of two (i.e., $S /$ _ and L/L), the pattern of results did not change. That is, there was a significant gender by genotype interaction on IGT net score in block 1, but not in any of the subsequent blocks. In fact, the mean scores for the heterozygous groups were not significantly different from the $\mathrm{S} / \mathrm{S}$ homozygotes for both men and women; a pattern consistent with dominance for the lower functioning $S$ allele. One interpretation for the observed pattern of results is that individuals with an $S$ allele primarily use affective cues when making decisions under ambiguity, whereas, L/L homozygotes are better able to suppress affective responses due to increased coupling between the anterior cingulate cortex and the amygdala (Roiser et al., 2009). This decreased reliance on affective processing may enable L/L homozygotes to use other decision-making strategies such as heuristics or to rely on relevant personality traits such as sensation seeking; and the gender difference seen in the L/L homozygotes may reflect differential use of brain areas and/or decisionmaking strategies (Bolla et al., 2004).

Men homozygous for the $\mathrm{L}$ allele appear to be in jeopardy for making disadvantageous decisions under ambiguity. However, they do not appear to make disadvantageous decisions under conditions where more information about outcome probabilities is available. When situations are inherently ambiguous, like decisions to drink alcohol, men with the $\mathrm{L} / \mathrm{L}$ genotype might be at greatest risk. This, when coupled with evidence for an initial lower level of response to alcohol and higher alcohol intake (Hinckers et al., 2006) and enhanced sensitivity to the neurotoxic effects of alcohol (Heinz et al., 2004) suggests that $\mathrm{L} / \mathrm{L}$ men may be at elevated risk for alcohol problems. Our pattern of results is consistent with recent findings that $\mathrm{L} / \mathrm{L}$ homozygotes may be less sensitive to punishment-related information when compared to individuals with alternative 5-HTTLPR genotypes (e.g., Blair et al., 2008), and with the findings of Bolla et al. (2004) that men have more activation in the right lateral orbital frontal cortex, an area implicated in punishment, during IGT performance. More work is needed to further characterize the mechanisms of decisionmaking under ambiguity, and special attention should be paid to 5-HTTLPR genotype and gender.

Two recent reports, that used the same data set, have identified an association between 5-HTTLPR genotype and performance on the IGT (Homberg et al., 2008; van den Bos et al., 2008). Women with the S/S genotype chose more disadvantageously than those with the $\mathrm{L} / \mathrm{L}$ genotype and this effect was most pronounced as the IGT progressed (i.e., cards 41-50). Our findings are somewhat consistent with these results, in that we observed women carriers of the $S$ allele to choose more disadvantageously than women with the L/L genotype. However, we observed the effect in the early part of the IGT (cards 1-20). Both Homberg et al. (Homberg et al., 2008) and van den Bos et al. (van den Bos et al., 2008) analyzed the data in just two blocks (cards 1-40 and 41-100), which may have obscured the effects that we observed. In addition, neither of these studies tested males, which did not allow testing for a gender by genotype interaction. The largest sample size in these studies was 89 
(Homberg et al., 2008), in contrast to our more statistically powerful sample of 188 (117 women). Clearly, further work is required to fully characterize the effects of gender and 5-HTTLPR genotype on decision-making.

The results of the present study, albeit indirectly, add to convergent evidence that genetic variation in serotonin components differentially affect serotonin functioning in men and women (Weiss et al., 2005; Williams et al., 2003). However, because we did not directly measure any aspect of 5-HT function, we are unable to make clear statements regarding the relationship between specific aspects of 5-HT function and decision-making.

Our results did not support our hypothesis of an effect of a TPH2 intron-8 polymorphism (rs1386483) on decision-making. Although TPH2 polymorphisms are associated with executive function (Reuter et al., 2007) and response inhibition (Stoltenberg et al., 2006), we did not find an association between rs1386483 and IGT performance. That our finding is inconsistent with other studies of TPH2 genetic variants (e.g., Brown et al., 2005; Jollant et al., 2007; and Reuter et al., 2007) may be due to the fact that we did not assess the same polymorphism.

In the present study, IGT performance was not significantly correlated with several measures of impulsivity (i.e., Barratt Impulsiveness Scale, version 11-total and subscales; Stop Task performance-Go reaction time, Go Accuracy, or Stop Signal reaction time). The only exception was that IGT performance in block 5 was significantly, but weakly, correlated with Stop Signal Reaction Time, $r=0.14, N=188, p<0.05$. However, because this correlation matrix contained 35 comparisons, this result may be the result of a Type II error and should be interpreted cautiously. At least for those varieties assessed by the BIS-11 and the Stop Task, impulsivity does not appear to be an important influence on IGT performance (data not shown).

The present findings are consistent with previous reports of gender differences on the IGT (Bolla et al., 2004; Reavis and Overman, 2001; Weller et al., 2009). Within subjects analyses identified a highly significant block by gender effect whereby women made more advantageous choices than men in block 1 (i.e., under ambiguity), but by block 5 (i.e., under risk) women made significantly fewer advantageous choices than men. In fact, scores for women remained rather constant across Blocks 2 to 5, whereas scores for men showed gradual and steady improvement. This pattern of results suggests that men were better able than women to learn the outcome probabilities of their choices as the task progressed. However, when overall performance is considered, there was no significant gender difference. Gender differences were revealed only within subject performance across blocks. This pattern of results demonstrates the utility of dividing IGT performance into blocks, making it possible to index different decision-making processes. We did not assess other measures of learning in this study, but we agree with the suggestion by Jollant et al. (2007) that the involvement of learning processes in decision-making is important to understand and requires further study. Gender differences in IGT performance do not appear to be due to differences in computational skill (Overman et al., 2006) but to differential activation of areas of the prefrontal cortex such as the orbitofrontal cortex (Bolla et al., 2004) and the dorsolateral prefrontal cortex (Bolla et al., 2004; Overman et al., 2006). These studies, when combined with the literature reporting 5-HTTLPR differences in amygdala activation in response to threat or ambiguity, suggest that studies specifically designed to 
identify gender by 5-HTTLPR interactions in the activation of threat/loss aversion circuitry and in cognitive processes is necessary to fully characterize these systems.

When interpreting the present results, the following factors should be considered. First, it is unclear if our findings will generalize to non-Caucasian populations. For 5-HTTLPR, Gelernter, Kranzier, and Cubells (Gelernter et al., 1997) reported differences in allele frequencies and linkage disequilibrium blocks in African American, European American, and Japanese populations. For various TPH2 polymorphisms, Zhou et al. (Zhou et al., 2005) reported differences in allele frequencies and linkage disequilibrium blocks in Caucasian, African American, and Native American populations. Second, the present study was limited by the fact that 5-HTTLPR by TPH2 genotype interaction was not examined. Epistatic interactions are likely to exist among 5-HT system components (Stoltenberg, 2005); however, our relatively small sample size limited our ability to test them. Third, other genetic polymorphisms in the 5-HT system should also be considered. Fourth, we did not assay hormones or control for menstrual phase, both of which appear to be relevant in the function of the serotonin system and in decision-making (Birzniece et al., 2006; Reavis and Overman, 2001; van Honk et al., 2004).

To better understand 5-HTTLPR/gender mechanisms underlying decision-making, future studies should examine IGT performance in healthy individuals with respect to (a) serotonin levels (e.g., manipulated by acute tryptophan depletion), (b) amygdala/ventromedial prefrontal cortex activation, (c) state and trait anxiety, (d) learning, (e) working memory, and (f) use of heuristics. Future studies would also benefit from studying 5-HTTLPR genotype and gender with respect to other tasks that assess decision-making under ambiguity or risk. In addition, decision-making studies should look for a 5-HTTLPR by rs1386483 interaction, as well as interactions among other serotonin system genes.

Our results suggest that for healthy individuals the transition from decisions under ambiguity to decisions under risk may take place as early as the second block of the IGT, which is consistent with the findings of Weller et al. (2004). Such an effect would not be identified if performance on the IGT were analyzed as the total net score (e.g., Must et al., 2007) or by examining performance in the first and second halves of the task (e.g., Jollant et al., 2007). We did not obtain verbal reports from participants regarding their knowledge about the game, but performance on block 1 (first 20 choices) was uncorrelated with performance on blocks $2-5$, which were all positively intercorrelated, which is consistent with the ambiguity versus risk distinction.

In conclusion, our study provides evidence for a gender by 5-HTTLPR genotype interaction effect on decision-making under ambiguity. The observed pattern of results adds to convergent evidence for differential serotonin functioning for men and women grouped by 5-HTTLPR genotype. However, it is not clear whether this pattern of results was due to differential 5-HT function in adults or due to neurodevelopmental differences in relevant brain circuits that preceded task performance. Because the observed interaction was statistically significant only when outcomes were ambiguous, our finding supports the position that decisions under ambiguity and decisions under risk may be influenced by different underlying genetic architecture. 
Acknowledgments - This study was made possible by Grant Number 2 P20 RR016479 from the National Center for Research Resources (NCRR), a component of the National Institutes of Health (NIH); by a Governor's 2010 Individual Research Seed Grant (SDBOR/BHSU 2010-06-01); by a Nelson Summer Research Fellowship; and by a grant from the BHSU Faculty Research Committee. The authors thank Dr. Dan Bergey for genotyping assistance and Dr. Parthasarathi Nag for statistical advice. The authors also thank Kelley Aline, Bryan Batien, Denis Birgenheir, Melissa Lehmann, Ben Roman, and Jeanie Stockland for assistance with data collection and the volunteer participants, without whose efforts this research could not have been conducted. Thanks to anonymous reviewers and to Russ Poldrack, Eliza Congdon, and Melissa A. Munn for helpful comments on earlier versions of the manuscript.

\section{References}

Baumgarten, H. G., Grozdanovic, Z., 1999. Anatomy of central serotonergic Projection systems. In: Baumgarten, H.G., Gothert, M. (Eds.), Serotonergic Neurons and 5-HT Receptors in the CNS. Springer-Verlag, Berlin.

Bechara, A., Damasio, A. R., Damasio, H., Anderson, S. W., 1994. Insensitivity to future consequences following damage to human prefrontal cortex. Cognition 50, 7-15.

Bechara, A., Tranel, D., Damasio, H., 2000. Characterization of the decision-making deficit of patients with ventromedial prefrontal cortex lesions. Brain 123 (Pt 11), 2189-2202.

Bechara, A., Damasio, H., Tranel, D., Damasio, A. R., 2005. The Iowa Gambling Task and the somatic marker hypothesis: some questions and answers. Trends Cogn. Sci. 9, 159-162, discussion 162-174.

Birzniece, V., Backstrom, T., Johansson, I. M., Lindblad, C., Lundgren, P., Lofgren, M., Olsson, T., Ragagnin, G., Taube, M., Turkmen, S., Wahlstrom, G., Wang, M. D., Wihlback, A. C., Zhu, D., 2006. Neuroactive steroid effects on cognitive functions with a focus on the serotonin and GABA systems. Brain Res. Rev. 51, 212-239.

Biver, F., Lotstra, F., Monclus, M., Wikler, D., Damhaut, P., Mendlewicz, J., Goldman, S., 1996. Sex difference in 5HT2 receptor in the living human brain. Neurosci. Lett. 204, 25-28.

Blair, K. S., Finger, E., Marsh, A. A., Morton, J., Mondillo, K., Buzas, B., Goldman, D., Drevets, W. C., Blair, R. J. R., 2008. The role of 5-HTTLPR in choosing the lesser of two evils, the better of two goods: examining the impact of 5-HTTLPR genotype and tryptophan depletion in object choice. Psychopharmacology 196, 29-38.

Bolla, K. I., Eldreth, D. A., Matochik, J. A., Cadet, J. L., 2004. Sex-related differences in a gambling task and its neurological correlates. Cereb. Cortex 14, 1226-1232.

Brand, M., Labudda, K., Markowitsch, H. J., 2006. Neuropsychological correlates of decision-making in ambiguous and risky situations. Neural Netw. 19, 1266-1276.

Brand, M., Recknor, E. C., Grabenhorst, F., Bechara, A., 2007. Decisions under ambiguity and decisions under risk: correlations with executive functions and comparisons of two different gambling tasks with implicit and explicit rules. J. Clin. Exp. Neuropsychol. 29, 86-99.

Brown, S. M., Peet, E., Manuck, S. B., Williamson, D. E., Dahl, R. E., Ferrell, R. E., Hariri, A. R., 2005. A regulatory variant of the human tryptophan hydroxylase-2 gene biases amygdala reactivity. Mol. Psychiatry 10, 884-888.

Denk, F., Walton, M. E., Jennings, K. A., Sharp, T., Rushworth, M. F., Bannerman, D. M., 2005. Differential involvement of serotonin and dopamine systems in cost-benefit decisions about delay or effort. Psychopharmacology (Berl) 179, 587-596. 
Dolan, S. L., Bechara, A., Nathan, P. E., 2008. Executive dysfunction as a risk marker for substance abuse: the role of impulsive personality traits. Behav. Sci. Law 26, 799-822.

Gelernter, J., Kranzler, H., Cubells, J. F., 1997. Serotonin transporter protein (SLC6A4) allele and haplotype frequencies and linkage disequilibria in African- and European-American and Japanese populations and in alcohol-dependent subjects. Hum. Genet. 101, 243-246.

Haavik, J., Blau, N., Thony, B., 2008. Mutations in human monoamine-related neurotransmitter pathway genes. Hum. Mutat. 29, 891-902.

Hariri, A. R., Drabant, E. M., Munoz, K. E., Kolachana, B. S., Mattay, V. S., Egan, M. F., Weinberger, D. R., 2005. A susceptibility gene for affective disorders and the response of the human amygdala. Arch. Gen. Psychiatry 62, 146-152.

Heinz, A., Goldman, D., Gallinat, J., Schumann, G., Puls, 2004. Pharmacogenetic insights to monoaminergic dysfunction in alcohol dependence. Psychopharmacology 174, 561-570.

Heinz, A., Braus, D. F., Smolka, M. N., Wrase, J., Puls, I., Hermann, D., Klein, S., Grusser, S. M., Flor, H., Schumann, G., Mann, K., Buchel, C., 2005. Amygdala prefrontal coupling depends on a genetic variation of the serotonin transporter. Nat. Neurosci. 8, 20-21.

Heinz, A., Smolka, M. N., Braus, D. F., Wrase, J., Beck, A., Flor, H., Mann, K., Schumann, G., Buchel, C., Hariri, A. R., Weinberger, D. R., 2007. Serotonin transporter genotype (5-HTTLPR): effects of neutral and undefined conditions on amygdala activation. Biol. Psychiatry 61, 1011-1014.

Hinckers, A. S., Laucht, M., Schmidt, M. H., Mann, K. F., Schumann, G., Schuckit, M.A., Heinz, A., 2006. Low level of response to alcohol as associated with serotonin transporter genotype and high alcohol intake in adolescents. Biol. Psychiatry 60, 282-287.

Homberg, J. R., van den Bos, R., den Heijer, E., Suer, R., Cuppen, E., 2008. Serotonin transporter dosage modulates long-term decision-making in rat and human. Neuropharmacology 55, 80-84.

van Honk, J., Schutter, D. J., Hermans, E. J., Putman, P., Tuiten, A., Koppeschaar, H., 2004. Testosterone shifts the balance between sensitivity for punishment and reward in healthy young women. Psychoneuroendocrinology 29, 937-943.

Jollant, F., Buresi, C., Guillaume, S., Jaussent, I., Bellivier, F., Leboyer, M., Castelnau, D., Malafosse, A., Courtet, P., 2007. The influence of four serotonin-related genes on decision-making in suicide attempters. Am. J. Med. Genet. B Neuropsychiatr Genet. 144B, 615-624.

Lee, B. T., Ham, B. J., 2008. Serotonergic genes and amygdala activity in response to negative affective facial stimuli in Korean women. Genes Brain Behav. 7, 899-905.

Lesch, K. P., Bengel, D., Heils, A., Sabol, S. Z., Greenberg, B. D., Petri, S., Benjamin, J., Muller, C. R., Hamer, D. H., Murphy, D. L., 1996. Association of anxiety-related traits with a polymorphism in the serotonin transporter gene regulatory region. Science 274, 1527-1531.

Maia, T. V., McClelland, J. L., 2004. A reexamination of the evidence for the somatic marker hypothesis: what participants really know in the Iowa gambling task. Proc. Natl. Acad. Sci. USA 101, 16075-16080.

Must, A., Juhasz, A., Rimanoczy, A., Szabo, Z., Keri, S., Janka, Z., 2007. Major depressive disorder, serotonin transporter, and personality traits: why patients use suboptimal decision-making strategies? J. Affect Disord. 103, 273-276.

Nishizawa, S., Benkelfat, C., Young, S. N., Leyton, M., Mzengeza, S., de Montigny, C., Blier, P., Diksic, M., 1997. Differences between males and females in rates of serotonin synthesis in human brain. Proc. Natl. Acad. Sci. USA 94, 5308-5313.

Ortiz, J., Artigas, F., Gelpi, E., 1988. Serotonergic status in human blood. Life Sci. 43, 983-990.

Overman,W. H., 2004. Sex differences in early childhood, adolescence, and adulthood on cognitive tasks that rely on orbital prefrontal cortex. Brain Cogn. 55, 134-147. 
Overman, W., Graham, L., Redmond, A., Eubank, R., Boettcher, L., Samplawski, O., Walsh, K., 2006. Contemplation of moral dilemmas eliminates sex differences on the Iowa gambling task. Behav. Neurosci. 120, 817-825.

van den Bos, R., Homberg, J., Gijsbers, E., den Heijer, E., Cuppen, E., 2008. The effect of COMT $\mathrm{Val}(158)$ Met genotype on decision-making and preliminary findings on its interaction with the 5-HTTLPR in healthy females. Neuropharmacology 56, 493-498.

van der Plas, E. A., Crone, E. A., van den Wildenberg, W. P., Tranel, D., Bechara, A., 2008. Executive control deficits in substance-dependent individuals: a comparison of alcohol, cocaine, and methamphetamine and of men and women. J. Clin. Exp. Neuropsychol., 1-14.

van der Plasse, G., La Fors, S. S., Meerkerk, D. T., Joosten, R. N., Uylings, H. B., Feenstra, M. G., 2007. Medial prefrontal serotonin in the rat is involved in goal-directed behaviour when affect guides decision making. Psychopharmacology (Berl) 195, 435-449.

Reavis, R., Overman, W. H., 2001. Adult sex differences on a decision-making task previously shown to depend on the orbital prefrontal cortex. Behav. Neurosci. 115, 196-206.

Reuter, M., Ott, U., Vaitl, D., Hennig, J., 2007. Impaired executive control is associated with a variation in the promoter region of the tryptophan hydroxylase 2 gene. J. Cogn. Neurosci. 19, 401-408.

Rogers, R. D., Tunbridge, E. M., Bhagwagar, Z., Drevets,W. C., Sahakian, B. J., Carter, C. S., 2003. Tryptophan depletion alters the decision-making of healthy volunteers through altered processing of reward cues. Neuropsychopharmacology 28, 153-162.

Roiser, J. P., Rogers, R. D., Cook, L. J., Sahakian, B. J., 2006. The effect of polymorphism at the serotonin transporter gene on decision-making, memory, and executive function in ecstasy users and controls. Psychopharmacology (Berl) 188, 213-227.

Rosier, J. P., de Martino, B., Tan, G. C. Y., Kumaran, D., Seymour, B., Wood, N. W., Dolan, R. J., 2009. A genetically mediated bias in decision making driven by failure of amygdala control. J. Neurosci. 29, 5985-5991.

Schilt, T., Goudriaan, A. E., Koeter, M. W., van den Brink, W., Schmand, B., 2008. Decision making as a predictor of first ecstasy use: a prospective study. Psychopharmacology (Berl). 203, 519.

Stoltenberg, S. F., 2005. Epistasis among presynaptic serotonergic system components. Behav. Genet. 35, 199-209.

Stoltenberg, S. F., Glass, J. M., Chermack, S. T., Flynn, H. A., Li, S., Weston, M. E., Burmeister, M., 2006. Possible association between response inhibition and a variant in the brain-expressed tryptophan hydroxylase-2 gene. Psychiatr. Genet. 16, 35-38.

Tevendale, H. D., Lightfoot, M., Slocum, S. L., 2008. Individual and environmental protective factors for risky sexual behavior among homeless youth: an exploration of gender differences. AIDS Behav. 13, 154-164.

Weiss, L. A., Abney, M., Cook Jr., E. H., Ober, C., 2005. Sex-specific genetic architecture of whole blood serotonin levels. Am. J. Hum. Genet. 76, 33-41.

Weller, J. A., Levin, I. P., Bechara, A., 2009. Do individual differences in Iowa Gambling Task performance predict adaptive decision making for risky gains and losses? J. Clin. Exp. Neuropsy 29, 1-12.

Williams, R. B., Marchuk, D. A., Gadde, K. M., Barefoot, J. C., Grichnik, K., Helms, M. J., Kuhn, C. M., Lewis, J. G., Schanberg, S. M., Stafford-Smith, M., Suarez, E. C., Clary, G. L., Svenson, I. K., Siegler, I. C., 2003. Serotonin-related gene polymorphisms and central nervous system serotonin function. Neuropsychopharmacology 28, 533-541.

Yonan, A. L., Palmer, A. A., Gilliam, T. C., 2006. Hardy-Weinberg disequilibrium identified genotyping error of the serotonin transporter (SLC6A4) promoter polymorphism. Psychiatr. Genet. $16,31-34$. 
Zhou, Z., Roy, A., Lipsky, R., Kuchipudi, K., Zhu, G., Taubman, J., Enoch, M. A., Virkkunen, M., Goldman, D., 2005. Haplotype-based linkage of tryptophan hydroxylase 2 to suicide attempt, major depression, and cerebrospinal fluid 5-hydroxyindoleacetic acid in 4 populations. Arch. Gen. Psychiatry 62, 1109-1118. 